pounds on each square inch of surface. M. Tissandier, in describing this simple experiment in the pages of $L a$ Nature, has suggested that a few imprisoned flies or other insects may without any cruelty or hurt do duty as divers within the miniature diving-bell, and afford proof that life can go on in the inclosed air even though below the surface of water.

In speaking in a former article of the subject of inertia we mentioned the following familiar trick: a number of the round wooden "men" used in playing the game of draughts are piled up in a column one upon another. If the lowest one of the pile is dextrously hit with the edge of a paper-knife or other suitable article it may be knocked away from under the others without overthrowing the others. Fig. 27 shows how the experiment is arranged, the narrow slip of wood which serves as the lid of the box being here used as the weapon. Beginners in science must not mistake the meaning of the term incrtia as applied to matter. Matter is not in itself lazy or inert. But it possesses the property of mass, and to set mass in motion requires the expenditure of energy. If we skilfully

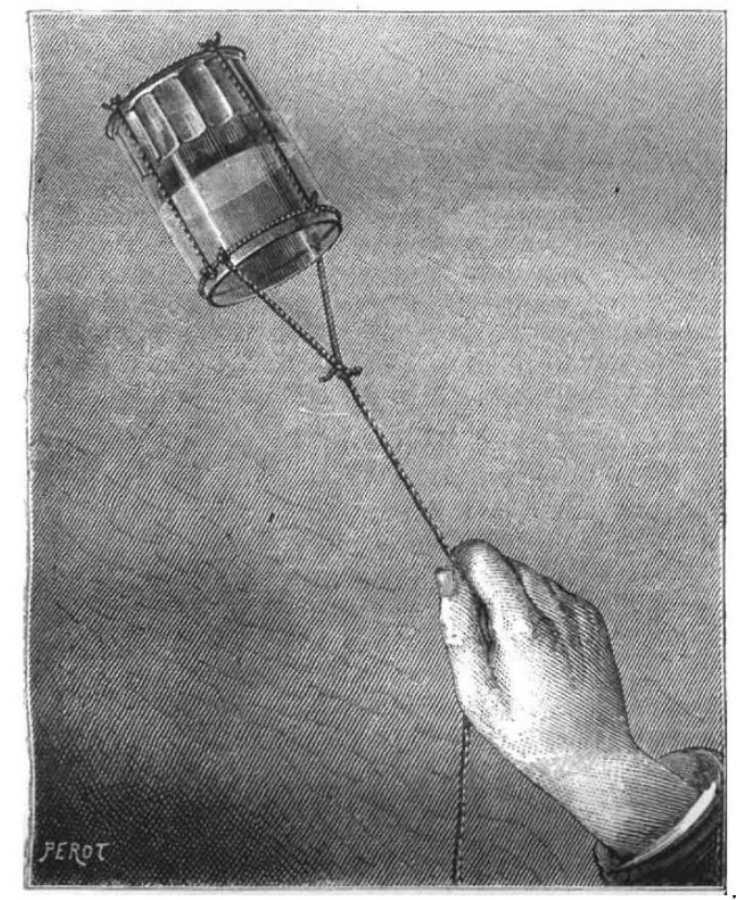

Fig. 30.

spend the energy of the rapid blow upon the one draughtsman, it is knocked away before there is time for any considerable part of the energy to be imparted to the others that are piled upon it.

Another simple experiment, depending partly upon the inertia of matter and partly upon elasticity, is often shown as an after-dinner trick. Upon a linen tablecloth is placed a threepenny-piece between two pennies or other larger and thicker coins. Over this an empty wine-glass is placed, and the puzzle is how to get out the smaller coin without touching the glass. The very simple operation of scratching with the finger-nail upon the cloth, as shown in Fig. 28, suffices to accomplish the trick, for the little coin is seen to advance gently towards the finger until it has moved completely away from under the glass. The fibres of the linen cloth are elastic; when you scratch with your finger-nail they are drawn gently forward until the force of their elasticity becomes too great and they fly back, to be once more drawn forward, again to slip back, and so on. While the fibres are drawn forward slowly, they drag the coin with them to a minute distance. But when the slip occurs and they fly backward, they do so very rapidly, and slip back under the coin before there is time for the energy of their movement to be imparted to the coin to set it in motion. So the coin is gradually carried forward over the surface of the cloth.

We will next give a simple experiment which illustrates the principle that a substance which is very weak in one direction may be very strong in another, the "strength" of the material (that is to say, the resistance it offers before it will break) depending on the way in which a force is applied to it. It is possible to lift a decanter full of water by means of a single straw. To do this the straw must be bent as Fig. 29 shows, so that the weight comes longitudinally upon the straw. The straw is a very weak thing if it has to resist a force applied laterally. Lay a single straw horizontally, so that the two ends are supported, and then hang weights on to the middle of it: a very few ounces will break it across. But let the weights be fixed to one end of the straw, and the straw itself be hung downwards so that the pull is exerted along it, and it will support one or two pounds at least. W'hen bent, as in the figure inside the bottle, most of the weight is applied as a thrust against the end of the straw; the bottle tilts slightly until the centre of gravity of the whole is below the point from which it hangs between finger and thumb; but in this position the sideway thrust against the middle of the straw is very small, and the material is strong enough to stand the strain to which it is subjected lengthways.

Lastly we offer an illustration (Fig. 30) of an experiment known to every schoolboy. A can or jar containing water may be whirled round the head without spilling a single drop, provided the motion be sufficiently rapid. When a moving body is subjected to the constraining action of a force which acts, like the pull of a string held in the hand, towards a fixed centre, the result is a motion around the centre of force. Were it not for the constraining force the moving body would fly away at a tangent ; and to the reaction exerted successively in all directions away from the centre the name "centrifugal force" was formerly given. The water in the can, being heavy, is also subjected to this so-called centrifugal force as it moves around the fixed centre, and hence it does not fall out of the can while passing through the inverted position in the air if its speed be sufficiently accelerated.

\section{THE GERMINATION OF WELWITSCHIA MIRABILIS}

H AVING been supplied, through the kindness of the Director of Kew Gardens, with young seedlings of Welwitschia mirabilis, I have been enabled to draw some fresh conclusions as to the homology of the large leaf structures, which have hitherto been described as persistent cotyledons. It is true this description has been confessedly provisional, since the process of germination has not hitherto been traced.

The seeds germinate in a manner corresponding in the main with that described by Strasburger for Ephedra campylopoda ("Conif. und Gnet.," p. 320). The radicle first breaks through the testa, the point of perforation depending apparently upon the position of the seed during germination. The cotyledons also break through the testa, but at a different point from the radicle. The cotyledons are two in number; in one case I observed three, one being smaller than the others. They free themselves entirely from the seed, and expand to a length of $I$ inch to $I_{2}^{\frac{1}{2}}$ inch, with a breadth of $\frac{1}{8}$ inch, or rather more; it is possible, however, that they may by growth attain a larger size. The cotyledons when expanded are green, though while still in the seed they are yellow. 
Their form is linear, margin entire, glabrous. Each has two main fibro-vascular bundles parallel to one another, and two or more lateral ones, also parallel to these; they all give off lateral bundles which anastomose freely. The hypocotyledonary portion of the stem extends to a length of about one to two inches; it is compressed in a plane parallel to that of the cotyledons, and is slightly swollen immediately below the point of junction with them.

Though the cotyledons are completely withdrawn from the seed at an early stage, a physiological connection is kept up between the seedling and the endosperm by a peculiar structure, produced apparently by a lateral swelling of the hypocotyledonary portion of the stem. The time and manner of its development I have not yet been able to ascertain, but in one seedling of twelve days it was found lying parallel to the cotyledons, these being still inclosed in the endosperm, whereas in the mature seeds I have not been able as yet to see any trace of it.

This structure remains in close connection with the endosperm, and is probably useful in transferring the nutritive substances from it to the embryo after the cotyledons have been withdrawn. As far as I can see at present, this lateral structure is produced merely by a process of lateral extension of tissues. The fibro-vascular bundles curve slightly into the protrusion, but I have observed no special modification of the tissues further than a lateral extension. If this be the case, it may be considered morphologically as an emergence.

It has been already observed by Strasburger ("Angiospermen und Gymnospermen," p. I55, Plate xxii., Figs. $90,91,93)$ that in the ripe embryo of Welwitschia an apical papilla is to be seen between the cotyledons; but his observations were conducted only on embryos in mature but ungerminated seeds; and here, as in other members of the group, the plumule does not develop beyond this condition of a mere papilla till germination begins. In the young seedlings (about six weeks old) which I have had the opportunity of observing, the plumule consists of two leaves, decussating with the cotyledons, and between these there is an apical papilla. In the most advanced specimens now growing at Kew these leaves of the plumule are about one-sixteenth of an inch in length, but no further development of leaves is at present to be seen.

These observations suggested a comparison with the youngest specimens preserved in the Kew collections : the result is the discovery of evident traces of the bases of leaf-structures below the well-known pair of large leaves, in the form of ragged ends of fibro-vascular bundles, which run directly into the tissues of the stem. These earlier leaves appear to have been at right angles to those of the existing leaves of the plant, and we may with good reason conjecture that they were the cotyledons. Full proof of this will be afforded if the plants at present growing at Kew remain healthy. If this conjecture be true the pair of large perennial leaves are the first and only pair of leaves developed from the plumule, and not cotyledons, as they have been hitherto assumed to be.

Other interesting points in the germination of this plant, together with a description of its minute histology, must be deferred till a later notice. This I hope to be able to publish with illustrations in an early number of the Quarterly Fournal of Microscopical Science.

F. ORPEN BOWER

The Jodrell Laboratory, Royal Gardens, Kew, October 9

\section{NOTES}

In the second of a series of articles in the Pall Mall Gazette "On Vain Discourse," in the quaint and leisurely style of our remote forefathers, the writer speaks of " the talker who thinketh he hath a vocation to popularise science, not as some of our masters come forth to stir up interest in these matters, but from folly and emptiness." $\mathrm{He}$ then proceeds to define him :- "He is a great breeder of vain discourses, for he deemeth that the strong meat of knowledge will sit ill on dainty stomachs, and so sets himself to save them the digesting. He watereth first to the consistency of a small fact to the page, and sweeteneth with many a line of poetry; and if there be a tough morsel of reasoning or a sharp fragment of logical defining, that he carefully throweth aside, 'et pondera rerum minutissimis verbis frangit.' For seasoning there are divers sorts of lights or colours or smells to wonder at, and pictures and tales, and praise of the wonderful nineteenth century, and of science and of such as study it. And so there is made a thin and limpid pabulum, or extractum scientice dilutum, which will not harm the delicatest, nor indeed do them any good, though it be sweet to the taste and pleasant to the eyes, and have the savour of wisdom. For knowledge that is worthy of being attained needeth faithful striving and endeavour, and skill cometh not but by assiduity in act and exercise- $\chi \alpha \lambda \epsilon \pi \dot{\alpha} \tau d \dot{\alpha} \kappa \alpha \lambda \alpha$." The lecture season is now beginning, and it would be well that those who attend science lectures should learn to distinguish between the true and the false, and this they can easily do by applying the test given by the Pall Mall. The spread of efficient education. in science will either extinguish the popular lecture or greatly alter its character. We are glad to see the growth of outside opinion on the subject, as may be inferred from the article alluded to.

We regret to record the death of Dr. E. J. Sparks, F.R.C.P., of Mentone, which occurred at Crewkerne on the IIth instant. Dr. Sparks has been in failing health for several years, but he is one of those striking instances of what work can be done by an active mind in spite of physical weakness. He was well known as a constant contributor to the Medical Times, in which appeared the series of letters on the climate of the Riviera, which were afterwards developed into his excellent book on the Health-Resorts of the Riviera. The preparation of this work occupied the best portion of Dr. Sparks' later years, and it is only threemonths since he revisited several of the less frequented places on the Eastern Riviera for the sake of a second edition. The book is a truly scientific work. Statistics relating to climate and the various diseases for which the Riviera has been recommended have been collected and tabulated with the greatest diligence and care; and the experience of observers, both lay and medical, as to the beneficial influence of the climate is given with the greatest candour. Besides this work, Dr. Sparks published a few years ago a translation of Dr. King's "Therapeutics," the value of which was greatly enhanced by the introduction of a quantity of new matter carefully collected together from medical periodicals. It was a work of no small labour, necessitating as it did the transformation of all quantitative relations from the German into those employed in the English and American Pharmacopœias. It received on the other side of the Atlantic prompt appreciation in a manner both hurtful and complimentary. Before it could be reprinted from the stereotype plates sent over for the purpose, a pirated fac-simile edition was produced by a publisher who has hitherto forgotten to send a cheque. $\mathrm{He}$ brought to his medical practice an unusually thorough knowledge of the science of his profession, and a high-minded devotion ta the welfare of his patients which quickly secured the confidence of all who consulted him. In friendship he was staunch, loyal, and self-sacrificing, and his loss will be long felt by a wide circle of friends.

THE following are among the scientific and geographical publications announced for the present season:-By Mr. Murray: "Japan; its History, Traditions, and Religions, with the 